REPERTORIO 



\title{
EL TRIBUNAL DE JUSTICIA DE LA UNIÓN EUROPEA COMO ACTOR DE CONSTITUCIONALIDAD. REPERTORIO BIBLIOGRÁFICO ${ }^{1}$
}

\author{
CIRO MILIONE \\ Profesor Titular (A) de Derecho Constitucional \\ Universidad de Córdoba \\ M. ${ }^{a}$ DOLORES MONTERO CARO \\ Investigadora \\ Área de Derecho Constitucional \\ Universidad de Córdoba
}

\section{SUMARIO}

I. Nota preliminar. II. La cuestión prejudicial ante el TJUE. III. El TJUE ante la responsabilidad de los Estados miembros por el incumplimiento del Derecho de la Unión. IV. El TJUE y los principios generales del Derecho de la Unión. V. El TJUE en diálogo con otras jurisdicciones. VI. El TJUE y la protección de los derechos en ámbito europeo. VII. La jurisprudencia del TJUE.

«Es gibt noch Richter in Berlin...und in Luxemburg auch.»

\section{NOTA PRELIMINAR}

Es probable que la labor del TJUE haya pasado en gran medida desapercibida para una buena parte de la ciudadanía española, al menos, hasta el pasado mes de diciembre en coincidencia con la publicación de la sentencia de 21 de diciembre de 2016 y su eco mediático. Es igualmente probable que, como ya hiciera el legendario molinero de

1 Nota del equipo de redacción: Teoría y Realidad Constitucional agradece particularmente a los Sres. Kuerten y Azcárraga, de la Dirección de la Biblioteca del TJUE un primer listado de referencias bibliográficas — libros y selección de artículos - relativas al papel del TJUE, como actor de la constitucionalidad, procedente del catálogo internet de la Biblioteca del Tribunal (http://www.bib-curia.eu/client/curia).

El presente estudio se enmarca en el ámbito del proyecto $\mathrm{I}+\mathrm{D}$ «Construyendo un estándar común de protección de los derechos fundamentales en la Unión Europea» (DER 2013-41303-P, Subprograma de proyectos de investigación fundamental no orientada, convocatoria de 2013 del Ministerio de Economía y Competitividad, línea de Excelencia) dirigido por la Prof. ${ }^{a}$ A. Carmona Contreras. Quisiéramos agradecer los Profs. M.J. Agudo Zamora, O. Salazar Benítez por sus inestimables aportaciones que enriquecen ahora este trabajo y por su amable labor de revisión. No obstante, cualquier error, omisión o imprecisión es exclusivamente imputable a los autores. 
Sanssouci, ese día las víctimas de abusos bancarios hayan clamado a viva voz «; aún hay jueces en...Luxemburgo!»

Sea como fuere, a nuestro parecer el TJUE no ha dejado de ocupar, desde su creación en 1952, las mentes y las plumas de juristas atraídos por una institución con un cometido extraordinario: garantizar la correcta y uniforme aplicación de las normas comunitarias y contribuir por esa vía a la construcción de una verdadera Unión de Derecho. Este repertorio bibliográfico quiere ofrecer a nuestros lectores una perspectiva amplia sobre ese panorama doctrinal.

Dicha recopilación se ha llevado a cabo recurriendo a todas las herramientas que la moderna investigación jurídica pone a nuestra disposición. Han sido rastreadas numerosas publicaciones periódicas tanto españolas como extranjeras, especializadas en Derecho Constitucional, Derecho Comunitario, Derecho Internacional Público, Derecho Administrativo, etc. Cada resultado relevante ha sido seleccionado sobre la base del título de la aportación, de sus resúmenes, sumarios o índices. Ante los casos dudosos, nos hemos adentrado en la lectura del texto, para así determinar su lugar más oportuno dentro de un orden sistemático que se ha ido imponiendo sobre el modelo que, idealmente, habíamos construido desde el principio.

En su formato definitivo este trabajo consta de seis apartados principales dedicados a la cuestión prejudicial ante el TJUE; a los principios generales del Derecho Comunitario desde la perspectiva de ese Tribunal; a su protagonismo en el diálogo con otras jurisdicciones; a su papel en la protección de los derechos en ámbito europeo; y, finalmente, a su doctrina. Este último apartado, en particular, incluye una breve recopilación de las principales revistas (especializadas en Derecho Internacional, Comunitario, Constitucional, Administrativo, Laboral, Ambiental, Financiero, etc.) que publican secciones periódicas especificadamente dedicadas a la jurisprudencia del Tribunal de Luxemburgo y a sus comentarios.

Si bien este repertorio bibliográfico se compone de un gran número de estudios doctrinales, es probable que otros no hayan sido incluidos por mero descuido. De ser así, confiaremos en la indulgencia de nuestros lectores.

\section{LA CUESTION PREJUDICIAL ANTE EL TJUE}

Alonso García, R., «Cuestión prejudicial europea y tutela judicial efectiva (a propósito de las SSTC 58/2004, 194/2006 y 78/2010)», Cuadernos de Derecho Público, n. ${ }^{\circ} 38,2009$, pp. 11-30.

Arroyo Jiménez, L., «Sobre la primera cuestión prejudicial planteada por el Tribunal Constitucional: Bases, contenido y consecuencias», Indret: Revista para el análisis del Derecho, n. ${ }^{\circ}$ 4, 2011.

BAÑo León, J. M. y Alonso García, R., «El recurso de amparo frente a la negativa a plantear la cuestión prejudicial ante el Tribunal de Justicia de la Comunidad Europea», Revisa española de Derecho Constitucional, Año n. ${ }^{\circ} 10$, n. ${ }^{\circ} 29$, 1990, pp. 193-222.

BAÑo León, J. M., «El Tribunal Constitucional, Juez comunitario: amparo frente al no planeamiento de cuestión prejudicial (STC 58/2004)», Revista de Derecho Comunitario, n. ${ }^{\circ} 18,2004$, pp. 465-481. 
BAQUero CruZ, J., «De la cuestión prejudicial a la casación europea: reflexiones sobre la eficacia y la uniformidad del Derecho de la Unión», Civitas. Revista española de Derecho Europeo, n. ${ }^{\circ} 13,2005$, pp. 35-58.

Calvo Salinero, R., Pastoriza Vázquez, J. S., «La cuestión prejudicial ante el Tribunal de Justicia de la Unión Europea», Chico de la Cámara, P., y Galán Ruiz, J., (Dirs.), La revisión de actos en materia tributaria, 2016, pp. 993-1044.

Carrera Hernández, F. J., « ¿Son los Secretarios Judiciales órganos jurisdiccionales a los efectos del planteamiento de cuestiones prejudiciales ante el Tribunal de Justicia de la UE?», Revista General de Derecho Europeo, n. ${ }^{\circ}$ 38, 2016.

Cedó Perpinyà, M., «Las cuestiones prejudiciales ante el tribunal de justicia de la Unión Europea», Economist E Jurist, vol. 21, n. ${ }^{\circ} 170,2013$, pp. 36-41.

Cienfuegos Mateo, M., «La cuestión prejudicial de la Unión Europea», López CastiLLO, A. (Dir.), Instituciones y Derecho de la Unión Europea, vol. 2, 2015, pp. 335-403.

- Uueces nacionales, cuestión prejudicial comunitaria y tutela judicial efectiva en la Unión Europea», Goizueta Vértiz, J., y Cienfuegos Mateo, M., (Dirs.), La eficacia de los derechos fundamentales de la UE: cuestiones avanzadas, 2014, pp. 39-78.

— « Pueden las jurisdicciones internacionales plantear una cuestión prejudicial al Tribunal de Justicia? De nuevo sobre la noción comunitaria de jurisdicción de un Estado miembro», Civitas. Revista de Derecho Europeo, n. ${ }^{\circ} 41$, 2012, pp. 151-192.

— «Juez nacional — Tribunal de Justicia: la cuestión prejudicial», en BENEYTO Pérez, J. M. (et alii), (Coords.), Tratado de Derecho y políticas de la Unión Europea, vol. 5, 2009, pp. 549-624.

L Las sentencias prejudiciales del Tribunal de Justicia de las Comunidades Europeas en los estados miembros: estudio de la interpretación prejudicial y de su aplicación por los jueces $y$ magistrados nacionales, J. M. Bosch Editor, Madrid, 1998.

Cobreros Mendazona, E., «Efectos temporales de las sentencias prejudiciales de interpretación del Tribunal de Justicia de la Unión Europea», Revista Vasca de Administración Pública, n. ${ }^{\circ}$ 105, 2016, pp. 67-102.

—Las sentencias prospectivas en las cuestiones prejudiciales de interpretación del Derecho comunitario», Civitas. Revista española de Derecho Europeo, n. ${ }^{4} 4,2002$, pp. 631-647.

Criado GÁmez, J. M., «La inadmisibilidad de la cuestión prejudicial prevista en el artículo 267 del Tratado de Funcionamiento de la Unión Europea», Revista jurídica de Castilla y León, n. ${ }^{\circ}$ 24, 2011, pp. 7-34.

Cruz Villalón, P. y Requejo Pagés, J. L., «La relación entre la cuestión prejudicial y la cuestión de inconstitucionalidad», Revista de Derecho Comunitario Europeo, n. ${ }^{\circ} 50$, 2015, pp. 173-194.

De Faramiñán, G., y MuÑoz Rodríguez, M. C., «Las cuestiones prejudiciales españolas durante 2005 y 2006. Análisis y valoraciones de la práctica judicial», Revista de Derecho Comunitario Europeo, n. ${ }^{\circ} 32,2009$, pp. 179-238.

Díez-Hochleitner Rodríguez, J., "Algunas reflexiones acerca del planteamiento de cuestiones prejudiciales ante el Tribunal de justicia de la Unión Europea por los tribunales españoles», Pedraz Calvo, M., y Ordóñez Solís, D., (Coords.), El Derecho Europeo de la competencia y su aplicación en España: "Liber amicorum» en homenaje a Santiago Martínez Lage, 2014, pp. 363-384. 
Dougan, M., National remedies before the Court of Justice: issues of harmonization and differentiation, Hart Publishing Limited, Portland, Oregon, 2004.

Droin, A., «Primera cuestión prejudicial del Tribunal Constitucional francés al Tribunal de Justicia de la Unión Europea», Revista jurídica Universidad Autónoma de Madrid, n. ${ }^{\circ}$ 29, 2014, pp. 71-83.

Fraile Ortíz, M., «Negativa del juez nacional a plantear una cuestión prejudicial ante el Tribunal de Justicia de las Comunidades Europeas», Civitas. Revista española de Derecho Europeo, n. ${ }^{\circ}$ 7, 2003, pp. 433-466.

Huelin Martínez de Velasco, J., «Las implicaciones constitucionales del incumplimiento del deber de plantear cuestión prejudicial ante el Tribunal de Justicia de la Unión Europea: Una aproximación «post-Lisboa»», Civitas. Revista española de Derecho Europeo, n. ${ }^{\circ}$ 39, 2011, pp. 375-412.

IzQuiERdo SANS, C., «Cuestión prejudicial y artículo 24 de la Constitución española», Revista General de Derecho Europeo, n. ${ }^{\circ} 23,2011$.

Jimeno Bulnes, M., «La cuestión prejudicial», Pardo Iranzo, V. (et alii), (Coords.), El sistema jurisdiccional de la Unión Europea, 2013, pp. 173-210.

Lenaerts, K., EU procedural Law, Oxford University Press, Oxford, 2014.

Martín Arribas, J. J., y Dembour Van Overgerh, P., «La cuestión prejudicial a la luz del artículo 68 del Tratado de la Comunidad Europea», Revista de Derecho Comunitario Europeo, n. ${ }^{\circ}$ 9, 2001, pp. 321-348.

Martín Rodríguez, P. J., «La cuestión prejudicial como garantía constitucional: a vueltas con la relevancia constitucional del Derecho Comunitario. (A propósito de la STC 58/2004, de 19 de abril, asunto tasa fiscal sobre el juego)», Revista española de Derecho Constitucional, Año n. ${ }^{\circ}$ 24, n. ${ }^{\circ}$ 72, 2004, pp. 315-348.

Martínez Capdevila, C., «El recurso de anulación, la cuestión prejudicial de validez y la excepción de ilegalidad: ¿vías complementarias o alternativas?», Revista de Derecho Comunitario Europeo, n. ${ }^{\circ}$ 20, 2005, pp. 135-174.

Martínez Lafuente, A., «La cuestión prejudicial en el Derecho de la Unión Europea», Carta tributaria. Revista de opinión, n. ${ }^{\circ} 19,2016$, pp. 11-34.

Peláez Marón, J. M., «Ámbito de la apreciación prejudicial de validez de los actos comunitarios», Revista de Instituciones Europeas, vol. 5, n. ${ }^{\circ}$ 3, 1978, pp. 739-780.

Rincón GARcía LOygorRi, A., En el horizonte de la tutela judicial efectiva, el TJCE supera la interpretación restrictiva de la legitimación activa mediante el uso de la cuestión prejudicial y la excepción de ilegalidad, Universidad San Pablo-CEU, 2004.

SÁnchez Rodríguez, A. J., «Acceso de los órganos arbitrales nacionales al procedimiento prejudicial del TJUE», Revista General de Derecho Europeo, n. ${ }^{\circ}$ 35, 2015.

SARmiento Ramírez-Escudero, D., «Cuestión prejudicial y control previo de constitucionalidad. Comentario a la sentencia Melki del Tribunal de Justicia de la UE», Civitas. Revista española de Derecho Europeo, n. ${ }^{\circ} 37,2011$, pp. 97-110.

Soca I Torres, I., «El nuevo Reglamento del Tribunal de Justicia de la Unión Europea», Cuadernos europeos de Deusto, n. ${ }^{\circ} 49,2013$, pp. 109-131.

Tenorio Sanchez, P. J., «Tribunal Constitucional y cuestión prejudicial ante el Tribunal de Justicia de la Unión Europea», Diario La Ley, n. ${ }^{\circ}$ 7520, 2010. 


\section{EL TJUE ANTE LA RESPONSABILIDAD DE LOS ESTADOS MIEMBROS POR EL INCUMPLIMIENTO DEL DERECHO DE LA UNIÓN}

Aedo Barrena, C. E., «Responsabilidad de los estados miembros por incumplimiento del derecho comunitario: Contexto normativo y construcción jurisprudencial», Revista de Derechos Fundamentales, n. ${ }^{\circ}$ 2, 2008, pp. 13-45.

Cicci Salazar, G., «La responsabilidad del estado por violación del derecho comunitario. Jurisprudencia del tribunal de justicia», Ars Boni et Aequi, vol. 6, n. ${ }^{\circ}$ 1, 2010, pp. 9-27.

Cobreros Mendazona, E., «La responsabilidad por actuaciones judiciales. El último gran paso en la responsabilidad de los Estados por el incumplimiento del Derecho Comunitario», Civitas. Revista española de Derecho Europeo, n. ${ }^{\circ}$ 10, 2004, pp. 289-316.

Díez-Hochleitner Rodríguez, J., "La respuesta del TUE al incumplimiento de las sentencias del Tribunal de Justicia por los Estados miembros», Revista de Instituciones Europeas, vol. 20, n. ${ }^{\circ} 3,1993$, pp. 837-900.

Frutos Miranda, J., «El procedimiento por inejecución de las sentencias declarativas de incumplimiento: estado de la cuestión», Civitas. Revista española de Derecho Europeo, n. ${ }^{\circ} 35,2010$, pp. 409-437.

Martín Delgado, I., "La ejecución de las sentencias declarativas del incumplimiento del Derecho Comunitario», Civitas. Revista española de Derecho Europeo, n. ${ }^{\circ} 16,2005$, pp. 595-626.

Rivas Castillo, M. I., «Tribunal de Justicia de las Comunidades Europeas: recursos de incumplimiento. Recursos de anulación», Revista General de Derecho Administrativo, n. ${ }^{\circ}$ 6, 2004.

SÁenZ de Santamaría, P. A., «Primera multa coercitiva a un Estado miembro por inejecución de sentencia (Comentario a la sentencia del TJCE de 4 de julio de 2000, Comisión c. Grecia)», Revista de Derecho Comunitario Europeo, n. ${ }^{\circ}$ 8, 2000, pp. 493-518.

Sánchez Patrón, J. M., «La inejecución de sentencias del Tribunal de Justicia de la Unión Europea: la jurisprudencia en la materia a partir del caso español», Bou Franch, V. E., y Cervera Vallterra, M., (Coords.), El derecho de la Unión Europea: 20 años después de la adhesión de España, 2007, pp. 389-416.

Silva De Lapuerta, R., "Responsabilidad de un Estado miembro por los daños causados a los particulares como consecuencia de violaciones del Derecho de la Unión imputables a un órgano jurisdiccional nacional: TJ Sala Primera, S 28 Julio 2016. Asunto C-168/15: Tomášová», La Ley Unión Europea, n. ${ }^{\circ}$ 43, 2016.

\section{EL TJUE Y LOS PRINCIPIOS GENERALES DEL DERECHO DE LA UNIÓN}

1. El principio de primacía desde la perspectiva del TJUE

Álvarez García, V. J., «La primacía del Derecho comunitario sobre la Jurisprudencia Constitucional española y su efecto recentralizador», BAÑo LEón, J. M., (Coord.), Memorial para la reforma del Estado: Estudios en homenaje al Profesor Santiago Muñoz Machado, vol. 1, 2016, Tomo I, pp. 253-276. 
Arroyo Jiménez, L., «Hacia la normalización constitucional del Derecho de la Unión Europea. (A propósito de la STC 145/2012, de 2 de julio)», Civitas. Revista española de Derecho Europeo, n. ${ }^{\circ} 45,2013$, pp. 139-169.

Barrero Ortega, A., «A vueltas con la primacía del Derecho de la Unión», Crónica Jurídica Hispalense: Revista de la Facultad de Derecho, n. 3 (extra), 2005, pp. 51-58.

Biglino Campos, M. P., «La primacía del Derecho comunitario: la perspectiva española», Revista General de Derecho Constitucional, n. ${ }^{\circ}$ 3, 2007, p. 2.

Cobreros Mendazona, E., «La aplicación del principio de primacía del Derecho de la Unión Europea por la Administración», Revista Vasca de Administración Pública. Herri-Arduralaritzako Euskal Aldizkaria, n. 103 (Septiembre-diciembre), 2015, pp. 171-207.

Cuena Casas, M., «La primacía del Derecho comunitario: luces y sombras», Revista General de Legislación y Jurisprudencia, n. ${ }^{\circ}$ 4, 2000, pp. 459-488.

Escobar Hernández, C., y Ojinaga Ruiz, M. R., «La primacía del derecho de la Unión Europea», Beneyto Pérez, J. M. (et alii), (Coords.), Tratado de Derecho y políticas de la Unión Europea, vol. 4, 2011, pp. 441-486.

Fernández Farreres, G. J., «Derecho de la Unión Europea y derecho nacional: problemas de articulación jurídica desde la consideración del principio de primacía del derecho comunitario y posibles soluciones», Justicia administrativa: Revista de Derecho Administrativo, n. ${ }^{\circ}$ 50, 2010, pp. 11-24.

GonZÁlez Alonso, L. N., «¿Fundamentalismo constitucional en Luxemburgo?. El Tribunal de Justicia y los límites de la autonomía del sistema jurídico de la Unión Europea a la luz del Dictámen 1/09», Civitas. Revista española de Derecho Europeo, n. ${ }^{\circ} 43,2012$, pp. $251-274$.

Groppi, T., «La «primauté» del Derecho europeo sobre el Derecho constitucional nacional: un punto de vista comparado», Revista de Derecho Constitucional Europeo, n. ${ }^{\circ}$, 2006, pp. 225-244.

LÁzAro, J., «La primacía del Derecho Comunitario», Escritura pública, n. ${ }^{\circ}$ 24, 2003 , pp. 30-32.

López VISO, M., «Doctrina de la primacía comunitaria, producto de la jurisprudencia del Tribunal de Justicia Comunitario, a partir de 1964», Revista General de Derecho, n. ${ }^{\circ}$ 572, 1992, pp. 4403-4407.

MARTín RodríGueZ, P. J., «Res judicata proveritate habetur c. primacía del Derecho Comunitario: ¿un combate por librar?: A propósito de la Sentencia del Tribunal de Justicia de 18 de julio de 2007, asunto C-119/05, Lucchini», Civitas. Revista española de Derecho Europeo, n. ${ }^{\circ} 24,2007$, pp. 521-557.

Matia Portilla, F. J., «Primacía del Derecho de la Unión y derechos constitucionales. En defensa del Tribunal Constitucional», Revista española de Derecho Constitucional, Año n. ${ }^{\circ} 36$, n. $^{\circ} 106,2016$, pp. 479-522.

Nettesheim, M., «El significado constitucional de la primacía del Derecho Comunitario/de la Unión», Civitas. Revista española de Derecho Europeo, n. ${ }^{\circ}$ 6, 2003, pp. 279-289.

Puissochet, J. P. (et alii), «La primacía del Derecho comunitario», Estudios de Derecho judicial, n. ${ }^{\circ}$ 95, 2006, pp. 19-69.

Rodríguez Iglesias, G. C., The supremacy of Community law over national law in the case law of the Court of Justice of the European Communities, Publisher, s.n., 2003. 
Ruiz-Jarabo y Colomer, D., «La primacía del Derecho comunitario europeo», Revista General de Derecho, n. ${ }^{\circ}$ 526-527, 1988, pp. 4497-4505.

Sieira Mucientes, S., «Primacía del Derecho de la Unión Europea y reforma de la Constitución española (Análisis crítico de la DTC 1/2004 de 13 de diciembre)», Icade: Revista de las Facultades de Derecho y Ciencias Económicas y Empresariales, ISSN 1889-7045, n. ${ }^{\circ}$ 66, 2005, pp. 67-92.

Vecchio, F., «Primacía del Derecho europeo y contralímites como técnicas para la relación entre ordenamientos», Revista de Derecho Constitucional Europeo, n. ${ }^{\circ}$ 17, 2012, pp. 67-102.

\section{El principio de efecto directo desde la perspectiva del TJUE}

Chalmers, D. y Barraso, L., «What Van Gend en Loos stands for», International Journal of constitutional Law, vol. 12, n. ${ }^{\circ} 1,2014$, pp. 105-134.

Derlén, M. y Lindhol, J., «Goodbye van Gend en Loos, hello Bosman? Using network analysis to measure the importance of individual CJEU judgments», European Law Journal, vol. 20, n. ${ }^{\circ}$ 5, 2014, pp. 667-687.

García de Enterría Martínez-Carande, E., «La suspensión cautelar inmediata de una ley nacional por el Tribunal de Justicia de las Comunidades Europeas (auto de 28 de junio de 1990, Comisión c Alemania)», Revista de Instituciones Europeas, vol. 17, n. $^{\circ} 3,1990$, pp. 875-884.

Gutiérrez Fons, J. A., «El legado de Van Gend en Loos», Unión Europea Aranzadi, n. ${ }^{\circ} 8-9,2013$, pp. 27-35.

MARTines, F., «Direct effect of international agreements of the European Union», European Journal of international Law, vol. 25, n. ${ }^{\circ}$ 1, 2014, pp. 129-147.

Millán Moro, L., «El principio de efecto directo: evolución según la jurisprudencia del Tribunal de Justicia», Beneyto PÉrez, J. M. (et alii), (Coords.), Tratado de Derecho y políticas de la Unión Europea, vol. 4, 2011, pp. 487-564.

Moreno-Tapias Rivas, I. y Fernández Vicién, C., «Un paso adelante en la aplicación del Derecho Comunitario por los jueces nacionales: el asunto Courage», Revista para el Análisis del Derecho, n. ${ }^{\circ}$ 1, 2002.

Phelan, W., «Supremacy, direct effect, and «Dairy Products» in the early history of European Law», International Journal of constitutional Law, vol. 14, n. . 1, 2016, pp. 6-25.

Prinssen, J. M., Direct effect: rethinking a classic of EC legal doctrine, Europa Law Publishing, Groningen, 2002.

Rassmussen, M., «Revolutionizing European Law: A history of the Van Gend en Loos judgment», International Journal of constitutional Law, vol. 12, n. ${ }^{\circ}$ 1, 2014, pp. 136-163.

Robin-Olivier, S., «The evolution of direct effect in the EU: Stocktaking, problems, projections», International Journal of constitutional Law, vol. 12, n. ${ }^{\circ}$ 1, 2014, pp. 165-188.

Sarmiento Ramírez-Escudero, D., «El Derecho de la Unión Europea: medio siglo de historia: comentario a la celebración del 50 aniversario de la sentencia Van Gend en Loos», Unión Europea Aranzadi, n. ${ }^{\circ} 8-9,2013$, pp. 37-42.

Signes DE Mesa, J. I., «Rememorando Van Gend en Loos en su 50. aniversario», Unión Europea Aranzadi, n. ${ }^{\circ}$ 8-9, 2013, pp. 43-52. 
Silva de Lapuerta, R., «La Sentencia Van Gend en Loos», Revista General de Derecho Europeo, n. ${ }^{\circ} 30,2013$.

UrCelay Lecue, M. C., «50 Aniversario de la sentencia «Van Gend en Loos» del TJUE sobre el principio de efecto directo», Actualidad jurídica Aranzadi, n. ${ }^{\circ}$ 865, 2013, pp. 14.

Weiler, J. H. H., «Van Gend en Loos: the individual as subject and object and the dilemma of European Legitimacy», European Journal of international Law, vol. 25, n. ${ }^{\circ} 1,2014$, pp. $83-84$.

\section{Otros principios}

Canedo Arrillaga, J. R. y Gordillo Pérez, L. I., «Tutela judicial, autonomía procedimental y efectividad del Derecho de la Unión», Revista General de Derecho Constitucional, ISSN 1886-6212, n. ${ }^{\circ} 15,2012$, p. 15.

De la Quadra-Salcedo Janini, T., «El Derecho Constitucional Comunitario in the age of balancing: control de constitucionalidad y principio de proporcionalidad», Cuadernos de Derecho Público, n. ${ }^{\circ}$ 18, 2003, pp. 207-239.

Estella de Noriega, A., El dilema de Luxemburgo: el Tribunal de Justicia de las Comunidades Europeas ante el principio de subsidiariedad, Centro de Estudios Ramón Areces, Universidad Carlos III, Madrid, 2000.

Ferreres Comella, V., «El Tribunal de Justicia de la Unión Europea y el principio constitucional de supletoriedad del Derecho estatal: un juicio socrático en Luxemburgo (Comentario a la STJUE de 24 de octubre de 2013. Comisión/España, C-15112)», Revista española de Derecho Constitucional, n. ${ }^{\circ} 103$, 2015, pp. 333-353.

López Castillo, A., «La aplicación (judicial) del derecho de la UE en los Estados miembros, especificidad, efectividad (eficacia directa, interpretación conforme y responsabilidad patrimonial por incumplimiento estatal) y primacía del derecho de la UE», López Castillo, A., (Dir.), Instituciones y Derecho de la Unión Europea, vol. 2, 2015, pp. 239-332.

López de los Mozos DíAz-MADroñero, A., «La normativización de la jurisprudencia del Tribunal de Justicia de las Comunidades Europeas», Revista General de Derecho Público Comparado, n. ${ }^{\circ}$ 3, 2008.

Martín y PÉrez de Nanclares, J., «Unidad y pluralismo en la jurisprudencia del Tribunal de Justicia de la Unión Europea. Hacia un refuerzo de la autonomía del derecho de la Unión Europea frente al Derecho Internacional», Rodrigo HeRnández, A. J., y García I SEgura, C., (Coords.), Unidad y pluralismo en el derecho internacional público y en la comunidad internacional, 2011, pp. 254-286.

Robles Morchón, G., «La influencia de los principios generales del derecho en el ordenamiento jurídico de la Unión Europea y la importancia de la jurisprudencia del Tribunal de Justicia», Beneyto Pérez, J. M., (et alii), (Coords.), Tratado de derecho y políticas de la Unión Europea, vol. 4, 2011, pp. 345-440.

Silva García, F., «La Unión Europea problemas constitucionales derivados de su estructura y funcionamiento institucional», Boletín Mexicano de Derecho Comparado, n. ${ }^{\circ} 104$, 2002, pp. 589-620. 


\section{EL TJUE EN DIÁLOGO CON OTRAS JURISDICCIONES}

\section{Aspectos generales}

Alonso García, R., "Guardar las formas en Luxemburgo», Revista General de Derecho Europeo, n. ${ }^{\circ}$ 28, 2012.

BACHMAIER WinTER, L., «Quo vadis - El TJUE y su papel en materia de cooperación penal al hilo de la reciente jurisprudencia sobre la orden de detención y entrega», Revista General de Derecho Europeo, n. ${ }^{\circ}$ 38, 2016.

Balaguer Callejón, F., «Los tribunales constitucionales en el proceso de integración europea», Revista de Derecho Constitucional Europeo, n. ${ }^{\circ}$ 7, 2007, pp. 327-378.

Cartabia, M. A., «El diálogo entre los tribunales a la hora del activismo constitucional del Tribunal de Justicia», Civitas. Revista española de Derecho Europeo, n. ${ }^{\circ}$ 22, 2007, pp. 199-236.

De Vergottini, G., «El diálogo entre tribunales», Teoría y realidad constitucional, n. ${ }^{\circ} 28$, pp. 345-359.

HeRnÁndez Ramos, M., «La relación entre la Justicia constitucional y el Tribunal de Justicia de la Unión Europea en el proceso de integración», Hernández Ramos, M., y Deluca, S., (Coords.), Tribunales en organizaciones de integración: Mercosur, Comunidad Andina y Unión Europea, Madrid, 2012, pp. 237-258.

Jesus DE PAZ, M., «El Espacio Judicial Europeo en materia civil y la «quinta libertad comunitaria»: La reforma del modelo Bruselas I», Civitas. Revista española de Derecho Europeo, n. ${ }^{\circ}$ 36, 2010, pp. 565-588.

Jiménez Benítez, W. G., «Controversias jurídicas en Europa. El Tribunal de Justicia Europeo frente al Derecho nacional», Diálogos de saberes: investigaciones y ciencias sociales, n. ${ }^{\circ}$ 40, 2014, pp. 37-54.

Lock, T., The European Court of Justice and international courts, Oxford Universtiy Press, Oxford, 2015.

Luther, J., «Jueces europeos y jueces nacionales: la Constitución del diálogo», Revista de Derecho Constitucional Europeo, n. ${ }^{\circ}$ 3, 2005, pp. 159-182.

Martinico, G., «Barking dogs sometimes bite! Un ensayo sobre la incidencia de la UE en el marco constitucional de los Estados miembros del este», Revista española de Derecho Europeo, n. ${ }^{\circ}$ 47, 2013, pp. 15-43.

PÉrez Tremps, P., «Justicia comunitaria, Justicia constitucional y Tribunales ordinarios frente al Derecho comunitario: Comentario a la Sentencia de la Corte Constitucional italiana número 170/1984, de 8 de junio», Revista española de Derecho Constitucional, Año n. ${ }^{\circ}$, n. n. ${ }^{\circ} 13,1985$, pp. 157-182.

SHANY, Y., The competing jurisdictions of International Courts and Tribunals, Oxford University Press, Oxford, 2003.

Soто DíAz, D., «Tribunales constitucionales y Tribunal de Justicia de la Unión Europea: el convulso vértice de la pirámide del sistema jurisdiccional europeo», Anuario da Facultade de Dereito da Universidade da Coruña, n. ${ }^{\circ}$ 18, 2014, pp. 363-390.

Ugartemendía Eceizabarrena, J. I., «¿Quién es el juez de los derechos fundamentales frente a la ley en el ámbito interno de aplicación del Derecho Comunitario?: reflexiones sobre el control iusfundamental del Derecho interno a la luz de la 
recepción nacional de los derechos fundamentales de la Unión Europea», Teoría y realidad constitucional, n. ${ }^{\circ} 20,2007$, pp. 401-433.

Vidal Prado, C., «Tribunales constitucionales nacionales y tribunal de justicia de las Comunidades Europeas», Carrasco Durán, M. (et alii), (Coords.), Derecho constitucional para el siglo XXI: actas del VIII Congreso Iberoamericano de Derecho Constitucional, vol. 1, Madrid, 2006, pp. 2337-2360.

\section{El TJUE en diálogo con el Tribunal Europeo de Derechos Humanos}

Bustos Gisbert, R., «El diálogo entre el Tribunal de Justicia y el Tribunal Europeo de Derechos Humanos en la construcción de un sistema europeo de defensa de los derechos fundamentales», Gómez Martín, V. (et alii), (Dirs.), Garantías constitucionales y Derecho penal europeo, Marcial Pons Ediciones Jurídicas y Sociales, Madrid, 2012, pp. 169-178.

—Tribunal de Justicia y Tribunal Europeo de Derechos Humanos: una relación de enriquecimiento mutuo en la construcción de un sistema europeo para la protección de los derechos», García Roca, F. J., y Fernández Sánchez, P. A., (Auts.), Integración europea a través de derechos fundamentales: de un sistema binario a otro integrado, Centro de Estudios Políticos y Constitucionales, Madrid, 2009, pp. 147-168.

Del Valle Gálvez, J. A., Rodríguez Iglesias, G. C., «El Derecho Comunitario y las relaciones entre el Tribunal de Justicia de las Comunidades Europeas, el Tribunal Europeo de Derechos Humanos y los Tribunales Constitucionales nacionales», Revista de Derecho Comunitario Europeo, n. ${ }^{\circ}$ 2, 1997, pp. 329-376.

Demuro, G., «Las relaciones entre la Corte de Justicia de las Comunidades Europeas y la Corte Europea de Derechos Humanos», Cuestiones constitucionales: Revista mexicana de Derecho Constitucional, n. ${ }^{\circ}$ 17, 2007.

Hermida Del Llano, C., «Una salida a los conflictos entre el Tribunal de Estrasburgo y el Tribunal de Luxemburgo", Persona y derecho: Revista de fundamentación de las Instituciones Jurídicas y de Derechos Humanos, n. ${ }^{\circ}$ 63, 2010, pp. 111-135.

Herranz Ballesteros, M., «Los Tribunales de Estrasburgo y Luxemburgo ante la protección de los Derechos fundamentales en supuestos de sustracción internacional de menores», Civitas. Revista española de Derecho Europeo, n. ${ }^{\circ} 44,2012$, pp. 41-60.

Ragone, S., «Las relaciones de los Tribunales Constitucionales de los Estados miembros con el Tribunal de Justicia y con el Tribunal Europeo de Derechos Humanos: una propuesta de clasificación», Revista de Derecho Constitucional Europeo, n. ${ }^{\circ} 16,2011$, pp. 53-90.

Repetto, G., «El argumento comparado en la jurisprudencia de los Tribunales de Estrasburgo y Luxemburgo: el pluralismo de los derechos fundamentales en el orden constitucional europeo», Revista de Derecho Constitucional Europeo, n. ${ }^{\circ}$ 20, 2013, pp. 277-236.

Sanz Caballero, S., «Interferencias en el Derecho Comunitario y el Convenio Europeo de Derechos Humanos: Luxemburgo versus Estrasburgo, ¿quién es la última instancia de los derechos fundamentales en Europa?» Revista de Derecho Comunitario Europeo, n. ${ }^{\circ} 17,2004$, pp. 117-160. 
SENDEN, H. C. K., Interpretation of fundamental rights in a multilevel legal system: an analysis of the European Court of Human Rights and the Court of Justice of the European Union, Intersentia, Antwerp, Belgium, 2011.

Tenorio SÁnchez, P. J., «Diálogo entre tribunales y protección de los derechos fundamentales en el ámbito europeo», Revista General de Derecho Europeo, n. . 31, 2013.

3. El TJUE en diálogo con la jurisdicción constitucional y los tribunales españoles

Bueno Armijo, A. M. y Magaldi, N., «La cuestión prejudicial y otras formas de diálogo con el tribunal de justicia de la Unión Europea: la singular participación de los jueces Españoles», Justicia administrativa, n. ${ }^{\circ}$ 53, 2011, pp. 41-72.

Díaz ABAD, N., «España, veinticinco años de presencia y jurisprudencia en el Tribunal de Justicia de la Unión Europea», Noticias de la Unión Europea, n. ${ }^{\circ} 315,2011$, pp. 17-27.

FernándeZ Alles, J. J., «La supremacía constitucional en el diálogo jurisdiccional TC TJUE», Revista General de Derecho Constitucional, n. ${ }^{\circ}$ 23, 2016.

IZQUIERDO SANS, C., «El choque entre la jurisdicción constitucional española y el Tribunal de Justicia de la Unión Europea en materia de derechos fundamentales», Niembro Ortega, R. (et alii), (Coords.), Jurisprudencia del Tribunal Constitucional español, 2012, pp. 185-238.

«Conflictos entre la jurisdicción comunitaria y la jurisdicción constitucional española (en materia de derechos fundamentales)», Civitas. Revista española de Derecho Europeo, n. ${ }^{\circ}$ 34, 2010, pp. 193-233.

Rodríguez IzQuierdo SERrano, M., «Pluralidad de jurisdicciones y tutela de derechos: los efectos de la integración europea sobre la relación entre el juez ordinario y el Tribunal Constitucional», Revista española de Derecho Constitucional, Año n. ${ }^{\circ} 36$, n. ${ }^{\circ} 107,2016$, pp. 117-150.

Rubio Llorente, F., «¿Divide et obtempera? Una reflexión desde España sobre el modelo europeo de convergencia de jurisdicciones en la protección de los Derechos», Revista española de Derecho Constitucional, Año n. ${ }^{\circ} 23$, n. $^{\circ}$ 67, 2003 , pp. 49-68.

Ugartemendía EcEIZABarRena, J. I., «La tutela judicial de los derechos fundamentales en el ámbito de aplicación nacional del Derecho de la Unión Europea. Recientes acotaciones del Tribunal de Justicia y del Tribunal Constitucional Español», Teoría y realidad constitucional, n. ${ }^{\circ} 32$, pp. 391-428.

\section{EL TJUE Y LA PROTECCIÓN DE LOS DERECHOS EN ÁMBITO EUROPEO}

1. La protección de los derechos fundamentales: aspectos generales

Agudo Zamora, M. J., «La protección de los derechos en la Unión Europea: claves para entender la evolución histórica desde el Tratado Constitutivo de la Comunidad Económica Europea al Tratado por el que se establece una Constitución para Europa», Revista de Derecho Constitucional Europeo, n. . 4, 2005, pp. 373-430. 
«Los derechos fundamentales en el proceso de integración europea: el papel del Tribunal Europeo de Justicia», VV. AA., La enseñanza de las ideas constitucionales en España e Iberoamérica: actas del congreso internacional sobre la enseñanza de las ideas constitucionales celebrado en la Universitat de Valencia de 16 al 21 de octubre de 2001, Marcial Pons, Valencia, 2001, pp. 153-174.

Alguacil González-Aurioles, J. A., «Ponderación, proporcionalidad y margen de apreciación en la jurisdicción europea de los derechos», Revista General de Derecho Europeo, n. ${ }^{\circ}$ 25, 2011.

Canedo Arrillaga, J. R. y Gordillo Pérez, L. I., «Los derechos fundamentales en la Unión Europea a la espera de Lisboa», Cuadernos europeos de Deusto, n. ${ }^{\circ}$ 39, 2008, pp. 27-59.

Carmona Contreras, A. M, «El espacio europeo de los derechos fundamentales: de la Carta a las constituciones nacionales», Revista española de Derecho Constitucional, n. ${ }^{\circ} 107$, mayo/agosto 2016, pp. 13-40.

DAusEs, M. A., The protection of fundamental rights in the legal order of the European Union: with emphasis on the institutional protection of those rights, Peter Lang, Frankfurt am Main, New York, 2010.

De Castro Sánchez, C., «Los principios generales en la jurisprudencia del Tribunal de Justicia de la Unión Europea: especial referencia a los derechos humanos», REINOsO Barbero, F., Principios generales del derecho: antecedentes históricos y borizonte actual, 2014, pp. 1065-1078.

Dunia MARinas SuÁrez, D., «Los talibanes en Luxemburgo: sanciones inteligentes y derechos fundamentales comunitarios», Revista Vasca de Administración Pública. Herri-Arduralaritzako Euskal Aldizkaria, n. ${ }^{\circ}$ 82, 2, 2008, pp. 197-234.

García Roca, F. J., «Originario y derivado en el contenido de la Carta de los Derechos Fundamentales de la Unión Europea: los test de constitucionalidad y convencionalidad», Revista de Estudios Políticos, 2003, pp. 165-190.

Gerards, J. H., European fundamental rights cases 1970/2014, Ars Aequi Libri, 2014.

GONZÁlEZ GONZÁLEZ, R., «Límites a la construcción de un orden público en materia de derechos fundamentales (A propósito de la sentencia del TJCE de 28 de marzo de 2000, Krombach c. Bamberski)», Revista de Derecho Comunitario Europeo, n. 8, 2000, pp. 593-618.

GonZÁlez PAscual, M. I., «EL TJUE como garante de los derechos en la UE a la luz de la sentencia Digital Rights Ireland», Revista de Derecho Comunitario Europeo, n. ${ }^{\circ}$ 49, 2014, pp. 943-971.

Janer Torrens, J. D., «La tutela de los derechos fundamentales en la adopción de medidas sancionadoras por la Unión Europea», Revista de Derecho Comunitario Europeo, Año n. ${ }^{\circ}$ 16, n. ${ }^{\circ} 43,2012$, pp. 773-806.

Jimena Quesada, L., «La consagración de los derechos fundamentales: de principios generales a texto fundacional de la Unión Europea», Cuadernos europeos de Deusto, n. ${ }^{\circ}$ 50, 2014, pp. 173-197.

MARINAs SuÁrez, D., El control iusfundamental de los actos legislativos de la Unión Europea. Una aproximación desde el Tribunal de Justicia de la Unión Europea, Thomson Reuters Aranzadi, Pamplona, 2015, 243 pp. 
Moitnho de Almeida de Carvalho, J. C., La protección de los derechos fundamentales en la jurisprudencia del tribunal de justicia de las comunidades europeas, Granada, 1992, Publisher s.n., 1992.

Montesinos Padilla, C., «A las puertas del TJUE. La frustrada flexibilización de las condiciones de acceso del particular», Civitas. Revista española de Derecho Europeo, n. ${ }^{\circ}$ 55, 2015, pp. 37-65.

Moure Pino, A. M., «La Jurisprudencia del Tribunal de Justicia de la Unión Europea y su contribución a la protección de los derechos y libertades fundamentales», Revista de Derecho: Universidad de Concepción, n. ${ }^{\circ}$ 233-234, 2013, pp. 53-70.

Muñoz Cordón, S., Coexistencia de sistemas de protección de derechos humanos en Europa, Publisher s.n., 1998.

Palacio GonzÁlez, J., «Órganos jurisdiccionales y tutela judicial efectiva de los derechos conferidos por el Ordenamiento Comunitario», Cuadernos europeos de Deusto, n. ${ }^{\circ} 10,1994$, pp. 61-100.

PÉrez ManZano, M., «Modificación de las normas del procedimiento ante el Tribunal de Justicia y ante el Tribunal de Primera Instancia a raíz de la entrada en vigor del Tratado de Niza», Revista General de Derecho Europeo, n. ${ }^{\circ}$ 2, 2003.

Rodríguez Iglesias, G. C., La protección de los derechos fundamentales en la jurisprudencia del Tribunal de Justicia de las Comunidades Europeas, Universidad Carlos III, Madrid, 1993.

Saiz Arnaiz, A., «El Tribunal de Justicia, los Tribunales Constitucionales y la tutela de los derechos fundamentales en la Unión Europea: entre el (potencial) conflicto y la (deseable) armonización: de los principios no escritos al catálogo constitucional, de la autoridad judicial a la normativa», Gómez FERnÁndez, I. (et alii), (Coords.), Constitución europea y constituciones nacionales, Ed. Tirant lo Blanch, Valencia, 2005, pp. 534-535.

SARmiento Ramírez-Escudero, D., «Who's afraid of the Charter? The Court of Justice, national courts and the new framework of fundamental rights protection in Europe», Common market Law Review, vol. 50, n. ${ }^{\circ}$ 5, 2013, pp. 1267-1304.

SARrión Esteve, J., El Tribunal de Justicia de Luxemburgo como garante de los derechos fundamentales, Dykinson, Madrid, 2015.

Ubeda Tarajano, F. E., «La labor del Tribunal de Justicia de la Unión Europea en orden a la protección de los Derechos Fundamentales», Boletín del Ministerio de Justicia, Año. 60, n. ${ }^{\circ}$ 2023, 2006, pp. 4251-4291.

VIÑ̃eta I Roca, F., «El Tribunal de Justicia de la Unión Europea y su jurisprudencia sobre derechos fundamentales», Actualidad laboral, n. ${ }^{\circ}$ 3, 2003, pp. 635-651.

VON BogdANDY, A. (et alii), «Un salvavidas para los derechos fundamentales europeos: principios básicos de una doctrina - Solange en el Derecho de la Unión frente a los Estados miembros», Revista General de Derecho Europeo, n. ${ }^{\circ} 28,2012$.

Walkila, S., Horizontal effect of fundamental rights in EU Law, Europa Law Publishing, Amsterdam, 2016.

Zoethout, C. M., «The Court and the charter, or, Who guards the Court of Justice of the EU under the new Constitution?», Proceedings of the 22nd IVR World Congress, Granada 2005, vol. 2, 2007, pp. 227-239. 


\section{Ciudadanía y extranjería}

Baquero Cruz, J., «El auto DemYanenko expulsión de ciudadanos de terceros Estados y TJCE», Revista de Derecho Comunitario Europeo, n. ${ }^{\circ} 19$, 2004, pp. 935-950.

Crespo Navarro, E. «La jurisprudencia del TJCE en materia de ciudadanía de la Unión: una interpretación generosa basada en la remisión al Derecho nacional y el principio de no discriminación por razón de la nacionalidad», Revista de Derecho Comunitario Europeo, n. ${ }^{\circ}$ 28, 2007, pp. 883-912.

Cuartero Rubio, M. V., «La jurisprudencia del Tribunal de Justicia de la Unión Europea en materia de extranjería. Las cuestiones prejudiciales planteadas por órganos judiciales españoles», Estudios jurídicos. Ministerio Fiscal, n. ${ }^{\circ}$ 1, 2003, pp. 915-951.

FERnÁndez Rojo, D., «La detención de extranjeros en situación irregular: impacto de la Directiva 2008/115/CE y la jurisprudencia del TJUE en la legislación española», Revista de Derecho Comunitario Europeo, n. ${ }^{\circ} 53,2016$, pp. 233-258.

Navamuel GonzÁlez, D., «Ciudadanía como categoría en la jurisprudencia del Tribunal de Justicia», Revista de Derecho de la Unión Europea, n. ${ }^{\circ}$ 3, 2002, pp. 461-465.

Rodríguez Moya, A., «Asylum and religious freedom. The ECJ position», Revista de Derecho Político, n. ${ }^{\circ}$ 94, 2015, pp. 115-140.

SARMiento Ramírez-Escudero, D., «A vueltas con la ciudadanía europea y la jurisprudencia expansiva del Tribunal de Justicia», Civitas. Revista española de Derecho Europeo, n. ${ }^{\circ}$ 26, 2008, pp. 211-227.

\section{Derecho a la igualdad y a la no discriminación}

Blázquez Peinado, M. D., «La perspectiva de derechos humanos en la acción de la Unión Europea en materia de discapacidad y su reflejo en la jurisprudencia del Tribunal de Justicia de la Unión Europea», Blázquez Peinado, M. D., y Biel PorTERO, I., (Coords.), La perspectiva de derechos humanos de la discapacidad: incidencia en la Comunidad Valenciana, 2012, pp. 85-118.

Carmona Cuenca, E., «La igualdad de género en el Tribunal Europeo de Derechos Humanos un reconocimiento tardío con relación al Tribunal de Justicia de la Unión Europea», Revista española de Derecho Constitucional, Año n. ${ }^{\circ}$ 35, n. ${ }^{\circ}$ 104, 2015, pp. 297-328.

Díaz LAFUENTE, J., «La protección de los derechos fundamentales frente a la discriminación por motivos de orientación sexual e identidad de género en la Unión Europea», Revista General de Derecho Constitucional, n. ${ }^{\circ} 17,2013$.

Freixes SAnjuán, T., «La igualdad de mujeres y hombres en el derecho de la Unión Europea. Especial referencia a la Jurisprudencia del Tribunal de Justicia de la Unión y del Tribunal Europeo de Derechos Humanos», Pastor Gosalbez, M. I. (et alii), Integración europea y género, 2014, pp. 15-65.

Nikolaidis, C. I., The right to equality in European human rights law: the quest for substance in the jurisprudence of the European courts, Routledge, Abingdon, 2015.

PÉrez de las Heras, B., «Las discriminaciones en sentido inverso en la jurisprudencia del Tribunal de Justicia: su compatibilidad con el principio constitucional de igualdad entre los ciudadanos de un Estado», Cuadernos europeos de Deusto, n. ${ }^{\circ} 1,1988$, pp. 75-92. 
Preciado Domènech, C. H., Igualdad y no discriminación en el Derecho de la Unión Europea, Bomarzo, Albacete, 2016.

Requena Casanova, M., «La discriminación por razón de la edad en la Unión Europea: el reconocimiento progresivo de derechos a través de la jurisprudencia», Revista General de Derecho Europeo, n. ${ }^{\circ}$ 31, 2013.

RodrígueZ-PIÑERo y Bravo-FERRER, M., «Cuestión prejudicial, derecho a la tutela judicial efectiva y primacía del principio de no discriminación sobre el Derecho comunitario derivado», Relaciones laborales: Revista crítica de teoría y práctica, n. ${ }^{\circ}$ 2, 2003, pp. 77-88.

Salazar Benítez, O., «La igualdad de hombres y mujeres en el acceso a la función pública en la jurisprudencia del Tribunal de Justicia de la Unión Europea: un ejemplo de la fragilidad de la discriminación positiva en el derecho comunitario», ADAM Muñoz, M. D., y Porro Herrera, M. J., (Coords.), Violencia y género: congreso internacional, 9, 10 de marzo de 2001, Córdoba, 2003, pp. 121-148.

\section{Derechos sociales en general}

Aguilar Calahorro, A., «La posición del tribunal de justicia de la Unión Europea frente a las medidas de la crisis económica», Revista de Derecho Constitucional Europeo, n. ${ }^{\circ} 24,2015$.

De Miguel Bárcena, J., «Los derechos sociales en la Unión Europea: comentarios a la última jurisprudencia del Tribunal de Justicia», Anuario da Facultade de Dereito da Universidade da Coruña, n. ${ }^{\circ}$ 12, 2008, pp. 1019-1034.

Jimena QuesadA, L., «La factibilidad de los derechos sociales en Europa: debate actual y perspectivas», Estudios de economía aplicada, vol. 27, n. . 3, 2009, pp. 743-766.

Martín Vida, M. A., «La dimensión social de la ciudadanía europea, con especial referencia a la jurisprudencia comunitaria en materia de libre circulación de los ciudadanos comunitarios y acceso a las prestaciones de asistencia social», Revista de Derecho Constitucional Europeo, n. ${ }^{\circ}$ 8, 2007, pp. 95-137.

PÉrez GonzÁlez, C., y IpPOLITo, F., «Eppur si muove!: nuevos caminos jurisprudenciales para la protección de los derechos sociales de los migrantes indocumentados en Europa», Revista de Derecho Comunitario Europeo, Año n. ${ }^{\circ}$ 20, n. ${ }^{\circ}$ 53, 2016, pp. 79-116.

SARMiento Ramírez-Escudero, D., «Los derechos sociales fundamentales y la protección de los trabajadores en la jurisprudencia del Tribunal de Justicia de la Unión Europea», Cuadernos Cantabria Europa, n. ${ }^{\circ} 11,2012$, pp. 69-94.

— «os conflictos entre libertades económicas y derechos fundamentales en la jurisprudencia del Tribunal de Justicia de la Unión Europea», Revista de Derecho Político, n. ${ }^{\circ} 81,2011$, pp. 379-412.

\section{Derechos laborales}

Gómez Gordillo, R., «Trabajo a tiempo parcial, jubilación y prohibición de discriminación sexual: revisión de la normativa española a la luz del Derecho de la Unión Europea y la jurisprudencia del TJUE y del Tribunal Constitucional», Revista de Derecho Comunitario Europeo, n. ${ }^{\circ} 47,2014$, pp. 157-179. 
Orlandini, G., «Los derechos fundamentales de los trabajadores en la jurisprudencia del Tribunal de Justicia de la Unión Europea», Revista de Derecho Social, n. ${ }^{\circ} 69$, 2015, pp. 57-78.

QuiÑones EscÁmez, A., «Otra lectura de la jurisprudencia del TJCE sobre desplazamiento de trabajadores (del asunto Arblade al Portugaia)», Revista de Derecho Comunitario Europeo, n. ${ }^{\circ}$ 12, 2002, pp. 435-453.

Rivas Castillo, M. I., «Tribunal de Justicia de Comunidades Europeas: acuerdos internacionales, protección de los trabajadores en caso de insolvencia del empresario, libre circulación de trabajadores e incumplimiento de directivas», Revista General de Derecho Administrativo, n. ${ }^{\circ}$ 2, 2003.

\section{Otros derechos}

Carretero García, A., «La protección de la salud de los consumidores: el principio de precaución en la Jurisprudencia del TJCE», Civitas. Revista española de Derecho Europeo, n. ${ }^{\circ}$ 6, 2005, pp. 547-592.

Embid Irujo, A., «El acceso a la justicia en materia ambiental en la jurisprudencia del Tribunal de Justicia de la Unión Europea», Revista Vasca de Administración Pública. Herri-Arduralaritzako Euskal Aldizkaria, n. ${ }^{\circ}$ 99-100, 2014, pp. 1207-1229.

López BASAgurEN, A., «La interpretación divergente entre el TEDH y el TJCE sobre el derecho a la inviolabilidad del domicilio de las personas jurídicas: a propósito de la jurisprudencia reciente», Civitas. Revista española de Derecho Europeo, n. ${ }^{\circ}$ 5, 2003, pp. 183-210.

López Portas, M. B., «La Configuración Jurídica Del Derecho al Olvido en el Derecho Español a tenor de la doctrina del TJUE», Revista de Derecho Político, n. ${ }^{\circ} 93,2015$, pp. $143-175$.

Martín Martínez, M. M., «Límites a la libre circulación de personas en la UE por razones de orden público, seguridad o salud pública en tiempos de crisis: una revaluación a la luz de la jurisprudencia del TJUE», Revista de Derecho Comunitario Europeo, n. ${ }^{\circ}$ 49, 2014, pp. 767-804.

Medina Ortega, M., «Sánchez Morcillo y las réplicas de la sentencia Aziz: Comentario a la STJUE de 17 de julio de 2014 (Sánchez Morcillo)», La Ley Unión Europea, mes 18, 2014, pp. 37-45.

Moreiro GonzÁlez, C. J., «El juez nacional de medidas cautelares y la tutela del orden público y del interés público de la Unión Europea», Revista de Derecho Comunitario Europeo, n. ${ }^{\circ}$ 54, 2016, pp. 473-516.

NinatTi, S., How do our judges conceive of democracy?: the democratic nature of the Community decision-making process under scrutiny of the European Court of Justice, New York University, School of Law, 2003.

Rodríguez IzQuierdo SERRANO, M., «El tribunal de justicia y los derechos en la sociedad de la información: privacidad y protección de datos frente a libertades informativas», Revista de Derecho Constitucional Europeo, n. ${ }^{\circ} 24,2015$.

- «a libertad de expresión y la jurisprudencia del Tribunal de Justicia de la Unión Europea», Estudios de Deusto: Revista de la Universidad de Deusto, vol. 62, n. ${ }^{\circ} 2$, 2014, pp. 93-119. 
SAFJAN, M., «De primacía, supremacía y derechos fundamentales en la Europa integrada: La Declaración del Tribunal Constitucional de 13 de diciembre de 2004 y el Tratado por el que se establece una Constitución», en López Castillo, A. (et alii), (Auts.), Constitución Española y Constitución Europea: análisis de la Declaración del Tribunal Constitucional (DTC 1/2004, de 13 de diciembre), 2005, pp. 51-75.

SARmiento Ramírez-Escudero, D., «La competencia de plena jurisdicción del Tribunal de Justicia de la UE frente a la justicia del Cadí», Civitas. Revista española de Derecho Europeo, n. ${ }^{\circ}$ 49, 2014, pp. 31-53.

7. El TJUE ante el reto de la adhesión de la UE al Convenio Europeo de Derechos Humanos

AzPitarte Sánchez, M., «Autonomía del ordenamiento de la Unión y Derechos Fundamentales: ¿presupuestos contradictorios? La adhesión al Convenio Europeo de Derechos Humanos como respuesta», Civitas. Revista española de Derecho Europeo, n. ${ }^{\circ} 48,2013$, pp. 37-74.

Cortés Martín, J. M., «Autonomía versus sumisión a un control externo en materia de derechos fundamentales consideraciones sobre el Dictamen TJUE n. ${ }^{\circ}$ 2/13 relativo a la adhesión al CEDH», Revista General de Derecho Europeo, n. ${ }^{\circ}$ 37, 2015.

«Adhesión al CEDH y la autonomía del Derecho de la Unión legitimación pasiva de la Unión y sus miembros y compatibilidad material», Revista General de Derecho Europeo, n. . 22, 2010.

Douglas-SCOTT, S., «Autonomy and fundamental rights: the ECJ's Opinion 2/13 on accession of the EU to the ECHR», Europarättslig tidskrift (Swedish European Law Journal), Special edition 2016.

Gambino, S., «Jurisdicción y justicia entre Tratado de Lisboa, Convenio Europeo de Derecho Humanos y ordenamientos nacionales», Revista de Derecho Constitucional Europeo, n. ${ }^{\circ} 13,2010$, pp. 83-120.

GonZÁLEZ VEGA, J. A., «La «teoría del big bang» o la creciente distancia entre Luxemburgo y Estrasburgo: Comentarios al Dictamen 2/13, del Tribunal de Justicia, de 18 de diciembre de 2014 sobre la adhesión de la unión Europea al Convenio Europeo de Derechos Humanos», La Ley Unión Europea, n. $.^{\circ} 25,2015$, pp. 17-50.

Guerra Martins, A. M., «Opinion 2/13 of the Court of Justice in the context of multilevel protection of fundamental rights and multilevel constitutionalism», Zeitschrift für Öffentliches Recht: ZÖR = Journal of Public Law, Bd. 71, 2016.

JACOBS, F. G., European Convention on Human Rights case-law in the jurisprudence of the European Court of Justice: impact of European Union accession to the European Convention on Human Rights, outline of presentation 4 November 2005, Publisher s.n., 2005.

Martín y PÉrez de Nanclares, J., «El TJUE pierde el rumbo en el dictamen 2/13: ¿merece todavía la pena la adhesión de la UE al CEDH?», Revista de Derecho Comunitario Europeo, n. ${ }^{\circ}$ 52, 2015, pp. 825-869.

—Cita con la ambición: el Tribunal de Justicia ante el desafío de la adhesión de la Unión el CEDH», Revista de Derecho Comunitario Europeo, n. ${ }^{\circ} 48,2014$, pp. 379-399. 
MuÑoz Machado, S., «Los tres niveles de garantías de los derechos fundamentales en la Unión Europea: problemas de articulación», Revista de Derecho Comunitario Europeo, n. ${ }^{\circ}$ 50, 2015, pp. 195-230.

O'MEARA, N., Lisbon, via Stockholm, Strasbourg and Opinion 2/13 prospects for citizen-centered protection of fundamental rights?, O'Meara, Noreen, The human face of the European Union, 2016.

Palacio GonzÁlez, J., «La protección de los Derechos Fundamentales por el Tribunal de Justicia de la UE: alcance y consecuencias de la futura adhesión de la UE al Convenio Europeo», Cuadernos europeos de Deusto, n. ${ }^{\circ} 40,2009$, pp. 161-179.

PAstor Ridruejo, J. A., «Sobre la adhesión de la Unión Europea a la Convención de Roma», Cuadernos europeos de Deusto, n. ${ }^{\circ} 43,2010$, pp. 43-51.

Soldevila Fragoso, S., «Dictamen 2/2013 del Tribunal de Justicia de 18 de diciembre de 2014, sobre la (¿imposible?) adhesión de la Unión Europea al Convenio Europeo para la Protección de los Derechos Humanos: Estado de la cuestión e incidencia en la práctica jurisdiccional española», Actualidad administrativa, n. ${ }^{\circ}$ 6, 2015.

8. La protección multinivel de los derechos fundamentales en Europa, tras las sentencias TJUE de 23 de febrero de 2013, asunto C-399/11 (caso Melloni vs. Ministerio Fiscal), y de 26 de febrero de 2013, asunto C-617/10 (caso Åklagaren contra Hans Åkerberg Fransson)

Arzoz Santisteban, X., «Karlsruhe rechaza la Doctrina Melloni del Tribunal de Justicia y advierte con el control de la identidad constitucional (comentario a la Sentencia del Tribunal Constitucional Federal Alemán de 15 de diciembre de 2015, 2 BVR 2735/14)», Civitas española de Derecho Europeo, n. ${ }^{\circ}$ 58, 2016, pp. 109-141.

BACHMAIER WINTER, L., «Más reflexiones sobre la sentencia Melloni: primacía, diálogo y protección de los Derechos fundamentales en juicios in absentia en el Derecho Europeo», Civitas. Revista española de Derecho Europeo, n. ${ }^{\circ}$ 56, 2015, pp. 153-180.

BERnitz, U., "The scope of the Charter and its impact on the application of the ECHR: the Åkerberg Fransson case on ne bis in idem in perspective», The EU Charter of Fundamental Rights as a binding instrument, Hart Publishing, Oxford, 2015, pp. 155-172.

Besselink, L. F. M., «The parameters of Constitutional conflict after Melloni», European Law Review, n. ${ }^{\circ}$ 4, 2014, pp. 531-552.

De Boer, N., «Addressing rights divergences under the Charter: Melloni-Case C-399/11, Stefano Melloni v. Ministerio Fiscal, Judgment of the Court (Grand Chamber) of 26 February 2013», Common market Law Review, vol. 50, n. ${ }^{\circ}$ 4, 2013, pp. 1083-1103.

De Visser, M., «Dealing with Divergences in Fundamental Rights Standards: Case C-399/11 «Stefano Melloni v. Ministerio Fiscal», Judgment (Grand Chamber) of 26 February 2013, not yet reported», Maastricht journal of European and comparative Law, vol. 20, n. ${ }^{\circ} 4,2013$, pp. 576-588.

Donaire Villa, F. J., «El diálogo del Tribunal Constitucional español con el Tribunal de Justicia de la Unión Europea sobre la Euroorden y los derechos fundamentales: el asunto Melloni», CEFLegal: Revista práctica de Derecho. Comentarios y casos prácticos, n. ${ }^{\circ} 174,2015$, pp. 63-78. 
Dubout, E., «Le niveau de protection des droits fondamentaux dans l’Union européenne: unitarisme constitutif versus pluralisme constitutionnel - Réflexions autour de l'arrêt Melloni», Cabiers de Droit Europeen, vol. 49, n. ${ }^{\circ}$ 2, 2013, pp. 293-317.

Figueruelo BurriezA, A., «El «diálogo aparente» entre el Tribunal Constitucional español y el Tribunal de Luxemburgo. Comentarios a propósito de la STC que resuelve el recurso de amparo n. ${ }^{\circ}$ 6922-2008 (Caso Melloni)», León Alonso, M., y Figueruelo Burrieza, A., (Dirs.), Derechos y libertades en la sociedad actual, 2014 , pp. 1-20.

GARcía SÁnchez, B., «Tribunal de Justicia de la Unión Europea - TJUE — Sentencia de 26.02.2013, Melloni, C-399/11 — «Cooperación policial y judicial en materia penal — Orden de detención europea — Procedimientos de entrega entre Estados miembros - Resoluciones dictadas a raíz de un juicio en el que el interesado no ha comparecido - Ejecución de una pena impuesta en rebeldía — Posibilidad de revisión de la sentencia». ¿Homogeneidad o estándar mínimo de protección de los derechos fundamentales en la Euroorden europea?», Revista de Derecho Comunitario Europeo, n. ${ }^{\circ} 46,2013$, pp. 1137-1156.

Gordillo Pérez, L. I., y TApia Trueba, A., «Diálogos, monólogos y tertulias. Reflexiones a propósito del caso Melloni», en Revista de Derecho Constitucional Europeo, n. ${ }^{\circ} 22$, 2014, pp. 245-270.

Groussot, X., «Clarifying or diluting the application of the EU Charter of Fundamental Rights?: the judgments in Åkerberg Fransson and Melloni from 26 February 2013», Principles of Law: function, status and impact in EU tax law, Edit. Cécile Brokelind, Amsterdam, 2014, pp. 51-89.

Haguenau-Moizard, C., «Identité constitutionnelle et mandat d'arrêt européen: l'exploitation de la jurisprudence «Melloni» par la Cour Constitutionnelle allemande», Europe: actualité du Droit Communautaire, vol. 26, n. ${ }^{\circ}$ 3, 2016, pp. 37-42.

IgLESIAS SÁNCHEZ, S., «TJUE, sentencia de 26.2.2013 (Gran Sala), Åklagaren y Hans Åkerberg Fransson, asunto C-617/10: Carta de los Derechos Fundamentales de la Unión Europea, ámbito de aplicación, artículo 51, aplicación del Derecho de la Unión, artículo 50, principio non bis in idem: la confirmación del ámbito de aplicación de la Carta y su interrelación con el estándar de protección», Revista de Derecho Comunitario Europeo, n. ${ }^{\circ} 46,2013$, pp. 1157-1175.

Lavranos, N. M., «The ECJ's judgments in Melloni and Åkerberg Fransson: une ménage à trois difficulté: (Stefano Melloni vs. Ministerio Fiscal, ECJ (Grand Chamber), judgment of 26 February 2013, C-399/11, Åklagaren vs. Hans Åkerberg Fransson, ECJ (Grand Chamber), judgment of 26 February 2013, C-617/10)», European Law reporter, n. ${ }^{\circ} 4,2013$, pp. 133-141.

Martín Rodríguez, P. J., «Tribunal Constitucional - Sentencia 26/2014, de 13 de febrero, en el recurso de amparo 6922-2008 promovido por Don Stefano Melloni», Revista de Derecho Comunitario Europeo, n. ${ }^{\circ} 48,2014$, pp. 603-622.

—Crónica de una muerte anunciada: comentario a la Sentencia del Tribunal de Justicia (Gran Sala), de 26 de febrero de 2013, Stefano Melloni, C-399/11», Revista General de Derecho Europeo, n. ${ }^{\circ}$ 30, 2013.

Ritleng, D., «De l'articulation des systèmes de protection des droits fondamentaux dans l'Union. Les enseignements des arrêts Akerberg Fransson et Melloni», Revue trimestrielle de Droit Europeen, vol. 49, n. ${ }^{\circ}$ 2, 2013, pp. 267-292. 
RAUCHEgGer, C., «The interplay between the Charter and national constitutions after Åkerberg Fransson and Melloni: has the CJEU embraced the challenges of multilevel fundamental rights protection?», The EU Charter of Fundamental Rights as a binding instrument, Hart Publishing, Oxford, 2015, pp. 93-131.

Reestman, J. H., «After Åkerberg Fransson and Melloni», European constitutional Law Review, vol. 9, Issue n. ${ }^{\circ}$ 2, 2013, pp. 169-175.

SARrión Esteve, J., «Supremacía constitucional y primacía del Derecho de la Unión Europea tras el caso Melloni», BAÑo LEÓN, J. M., (Coord.), Memorial para la reforma del Estado: Estudios en homenaje al Profesor Santiago Muñoz Machado, BAÑo León, J. M., vol. 1, (Tomo I), 2016, pp. 201-220.

Torres Pérez, A., «El Diàleg judicial sobre l'Euroordre: el cas Melloni en tres actes», Revista jurídica de Catalunya, vol. 113, n. ${ }^{\circ} 4$, 2014, pp. 985-1001.

-Melloni in three acts: From dialogue to monologue», European Constitutional Law Review, vol. 10, n. . 2, 2014, pp. 308-331.

Ugartemendía Eceizabarrena, J. I., y Ripoll Carulla, S., «La Euroorden ante la tutela de los Derechos Fundamentales. Algunas cuestiones de soberanía iusfundamental: A propósito de la STJ Melloni, de 26 de febrero de 2013, C-399/11», Civitas. Revista española de Derecho Europeo, n. ${ }^{\circ} 46,2013$, pp. 151-197.

VAN BOCKEL, W. B., «New wine into old wineskins: the scope of the Charter of Fundamental Rights of the EU after Åkerberg Fransson», European Law Review, vol. 38, n. ${ }^{\circ}$ 6, 2013, pp. 866-883.

VAN Rijckevorsel, E., «Droits fondamentaux (arrêt «Akerberg Fransson»; arrêt «Stefano Melloni c. Ministerio Fiscal»)», Revue du Droit de l'Union Européenne, n. ${ }^{\circ}$ 1, 2013, pp. 175-187.

\section{LA JURISPRUDENCIA DEL TJUE}

1. La jurisprudencia del TJUE como instrumento de integración europea

Carmona Fernández, N., «La jurisprudencia platónica del Tribunal de Luxemburgo», Carta tributaria. Monografías, n. ${ }^{\circ}$ 8, 2001, pp. 1-13.

Díez-Hochleitner Rodríguez, J., (et alii), (Coords.), Últimas tendencias en la jurisprudencia del Tribunal de Justicia de la Unión Europea (2008-2011), La Ley, Madrid, 2012.

Gordillo Pérez, L. I., y Martinico, G., Historias del país de las hadas: la jurisprudencia constitucionalizadora del Tribunal de Justicia, Civitas, Thomson Reuters, Navarra, 2015.

Green, A. W., Political integration by jurisprudence; the work of the Court of Justice of the European Communities in European political integration, Sijthoff, 1969.

López de los Mozos DíAz-MADroÑero, A., «La normativización de la jurisprudencia del Tribunal de Justicia de las Comunidades Europeas», Revista General de Derecho Público Comparado, n. ${ }^{\circ}$ 3, 2008.

O'NeILl, A., Decisions of the ECJ and their constitutional implications, Butterwoths, Londres, 1994. 


\section{Las Comunidades Autónomas en la jurisprudencia del TJUE}

Alberti Rovira, E. (et alii), Las comunidades autónomas en la Unión Europea, Centro de Estudios Políticos y Constitucionales, Madrid, 2005, 100 pp.

Alonso Arce, I., «La Abogada General del Tribunal de Luxemburgo respalda el Concierto», Forum fiscal de Bizkaia, mes 6, 2008, pp. 15-24.

Andrés SÁEnz de Santamaría, P., «Comunidades autónomas y repercusión económica ad intra de las sanciones pecuniarias en el recurso por incumplimiento ante el Tribunal de Justicia de la Unión Europea», Revista catalana de Dret Públic, n. ${ }^{\circ} 47$, 2013, pp. 40-60.

Alonso de León, S., «La posición de las Comunidades Autónomas ante el Tribunal de Justicia de la Unión Europea», Revista General de Derecho Europeo, n. ${ }^{\circ}$ 24, 2011.

Cienfuegos Mateo, M., «La legitimación procesal de las comunidades autónomas ante el Tribunal de Justicia de la Unión Europea tras la reforma de Lisboa», Unión Europea Aranzadi, n. ${ }^{\circ}$ 6, 2011, pp. 7-23.

Fernández Pérez, B., «El Tribunal de Justicia ante la cláusula de supletoriedad del Derecho estatal en los incumplimientos autonómicos del Derecho de la Unión Europea», Civitas. Revista española de Derecho Europeo, n. ${ }^{\circ}$ 52, 2014, pp. 117-139.

Huelin Martínez de Velasco, J., «Las posibilidades de intervención de las Comunidades Autónomas en los procesos por incumplimiento ante el Tribunal de Justicia de la Unión Europea», Revista española de la función consultiva, n. ${ }^{\circ}$ 15, 2011, pp. 33-48.

Martín y Pérez de Nanclares, J., y Urrea Corres, M., «Unión Europea y financiación autonómica: la jurisprudencia del Tribunal de Justicia sobre los sistemas tributarios de los entes territoriales subestatales», Revista d'estudis autonòmics i federals, n. ${ }^{\circ}$, 2009, pp. 37-84.

Ordóñez Solís, D., «La responsabilidad de las Comunidades Autónomas y de los entes locales españoles por la violación del Derecho de la Unión Europea: procedimientos de reclamación», Biglino Campos, M. P., y Delgado Del Rincón, L. E., (Coords.), El incumplimiento del derecho comunitario en el estado autonómico, 2011, pp. 143-182.

Pons Rafols, F. X., «El Tribunal de Justicia y la supletoriedad del Derecho estatal como garantía del cumplimiento autonómico del Derecho de la Unión Europea», Revista de Derecho Comunitario Europeo, n. ${ }^{\circ}$ 47, 2014, pp. 131-156.

SÁEz Moreno, S., «Los incumplimientos del derecho de la Unión Europea y su repercusión sobre las Comunidades Autónomas: Los asuntos Magefesa y vacaciones fiscales vascas», Revista jurídica Universidad Autónoma de Madrid, n. ${ }^{\circ}$ 32, 2015 , pp. 259-284.

Santiago Ortega, C., Las Comunidades Autónomas ante la jurisdicción comunitaria, Iustel, Madrid, 2006, 170 pp.

Sobrido Prieto, M., Las Comunidades autónomas ante el Tribunal de Justicia y el Tribunal de Primera Instancia de las Comunidades Europeas, Tirant Lo Blanch, Valencia, 2003, $518 \mathrm{pp}$.

Urrutia Libarona, I., «Defensa y promoción de las lenguas oficiales como razón imperiosa de interés general de la Unión Europea a la luz de la jurisprudencia del TJCE», 
Revista Vasca de Administración Pública. Herri-Arduralaritzako Euskal Aldizkaria, n. ${ }^{\circ}$ 83, 2009, pp. 227-266.

Zelaia Garagarza, M., «Las Comunidades Autónomas y la participación exterior y judicial ante el Tribunal de Justicia de la Unión Europea tras las reformas estatutarias», El Cronista del Estado Social y Democrático de Derecho, n. ${ }^{\circ} 26,2012$, pp. 30-43.

\section{Comentarios a la jurisprudencia del TJUE}

A continuación se señalan algunas de las revistas jurídicas que incluyen, entre sus apartados, secciones periódicas reservadas al análisis de las resoluciones más relevantes del TJUE.

Actualidad Jurídica Ambiental, (Centro Internacional de Estudios de Derecho Ambiental, CIEDA): desde 2011 (n. ${ }^{\circ} 1$, abril) sección «Jurisprudencia al día».

Aequalitas. Revista jurídica de igualdad de oportunidades entre mujeres y hombres, (Gobierno de Aragón: Instituto Aragonés de la Mujer): desde 2003 (n. ${ }^{\circ}$ 12, fasc. n. ${ }^{\circ}$ 1) sección «Derecho Comunitario».

Asamblea. Revista parlamentaria de la Asamblea de Madrid, (Asamblea de Madrid): desde 2009 (n. ${ }^{\circ} 21$ ) sección «Comentarios de jurisprudencia».

Cuadernos europeos de Deusto, (Ed. Universidad de Deusto, Deustuko Unibertsitatea, Instituto de Estudios Europeos): desde 1994 (n. ${ }^{\circ} 11$ ) sección «Jurisprudencia».

Derecho de los negocios, (Ed. Wolters Kluwer España): desde 2008 (n. ${ }^{\circ}$ 19, n. ${ }^{\circ}$ 216) sección «Unión Europea», rúbrica «Jurisprudencia TJUE».

IeZ: Ingurugiroa eta zuzenbidea = Ambiente y derecho, (Europar Ikerten Taldea): desde 2003 (n. ${ }^{\circ}$ 1) sección «Jurisprudencia de los Tribunales en materia ambiental».

La Ley Unión Europea, (Ed. Wolters Kluwer España): desde 2013 (n. ${ }^{\circ}$ 1) sección titulada «Jurisprudencia».

Revista Aranzadi de derecho ambiental, (Ed. Aranzadi): desde 2003 (n. ${ }^{\circ}$ 4) sección «Jurisprudencia. Comentarios».

Revista de Derecho Comunitario Europeo, (Centro de Estudios Políticos y Constitucionales): desde 2002 (Año n. ${ }^{\circ}$ 6, n. ${ }^{\circ}$ 11).

Revista de Instituciones Europeas, (Centro de Estudios Políticos y Constitucionales): desde 1974 (Vol. 1, n. ${ }^{\circ}$ 2) hasta su desaparición en 1996, sección «Jurisprudencia».

Revista española de Derecho Financiero, (Ed. Civitas): desde 2000 (n. $\left.{ }^{\circ} 105\right)$ sección «Jurisprudencia», rúbrica titulada «Jurisprudencia del TJUE».

Revista española de derecho internacional, (Ed. Marcial Pons): desde 2004 (Vol. 56, n. ${ }^{\circ}$ 1) sección «Jurisprudencia».

Revista General de Derecho Europeo, (Ed. Iustel): desde 2003 (n. ${ }^{\circ}$ 1) sección titulada «Comentarios de Sentencias».

Revista jurídica de Catalunya, (Ed. Acadèmia de Jurisprudència i Legislació de Catalunya, Col-legi d'Advocats de Barcelona): desde 1990 (Vol. 89, n. ${ }^{\circ}$ 1) hasta 2011 (Vol. 110, n. $^{\circ}$ 4) sección «Jurisprudencia Comunitaria», rúbrica titulada «Jurisprudencia del TJUE». 
TITLE: The European Court of Justice (ECJ) and its role in the European integration process. Bibliographic Repertoire

ABSTRACT: The present repertoire gathers the various doctrinal contributions (books, chapters, critical studies...) which have analyzed the European Court of Justice (ECJ) from different legal perspectives. In order to facilitate its consultation, the studies are classified in different sections according with its topic. Basically, all the contributions may be included under the ECJ preliminary ruling; the ECJ and member States liability in EU law fulfillment; the ECJ and the general principles of EU law; the ECJ and its dialogue with other jurisdictions; the ECJ's protection of rights; the ECJ's case law.

RESUMEN: El presente repertorio bibliográfico recoge diversos estudios (artículos doctrinales, capítulos de libros, monografías, comentarios jurisprudenciales) que ban abordado, desde distintas perspectivas, el papel del Tribunal de Justicia de la Unión Europea (TJUE) en el proceso de integración comunitaria. Para facilitar su consultación, esas publicaciones ha sido clasificadas en seis apartados principales: la cuestión prejudicial ante el TJUE; el TJUE ante la responsabilidad de los Estados miembros por el incumplimiento del Derecho de la Unión; el TJUE y los principios generales del Derecho de la Unión; el TJUE en diálogo con otras jurisdicciones; el TJUE y la protección de los derechos en ámbito europeo; la jurisprudencia del TJUE.

KEY WORDS: Repertoire, Court, Justice, Union, European.

Palabras Clave: Repertorio, Tribunal, Justicia, Unión, Europea.

FECHA DE RECEPCión: 15.01.2017 FECHA DE ACEPTACIÓN: 01.02.2017 
